\title{
Moderating factors influence the relative age effect in Australian cricket
}

\author{
Jonathan D Connor ${ }^{\text {Corresp., } 1,2}$, Ian Renshaw ${ }^{3}$, Kenji Doma ${ }^{1}$ \\ ${ }^{1}$ College of Healthcare Sciences, Sport and Exercise Science, James Cook University, Townsville, Queensland, Australia \\ 2 Department of Sport Sciences and Sport Medicine, National Cricket Centre, Brisbane, Queensland, Australia \\ 3 School of Exercise and Nutrition Sciences, Queensland University of Technology, Brisbane, QLD, Australia \\ Corresponding Author: Jonathan D Connor \\ Email address: jonathan.connor@jcu.edu.au
}

Background. The relative age effect is a commonly occurring phenomenon whereby there is a tendency for relatively older players to be over represented during high level competitions. This effect is often seen to diminish as player's age, however, there has been far less investigation on other potential moderating factors. Method. This study investigated the impact of the relative age effect, and potential moderating factors, within the talent selection process of Australian cricket. Relative age distribution of 2415 male and female junior and senior state level cricket players, who played in the Junior National Championships or State competition (senior level) between 2011 and 2015, were analysed. Results. Players born in the first quartile of the cricket season were significantly over represented in both male Under-15, Under-17, Under-19 and female Under-15 and Under-18 levels. However, there was no significant difference at the senior state level for either male or female cricketers. Further investigation of the relative age effect in the junior talent pathway revealed that male all-rounders, batters and pace bowlers, and female all-rounders and batters, born in first quartile were over represented. Right-handed batters and bowlers were also influenced by the relative age effect at all Junior National levels, while left-handed batters and bowlers were only influenced at the Under-15 and Under-17 levels. These results highlight the impact relative age has on junior cricket talent pathways, including sex, age, handedness and primary skills. Only state level, and lefthandedness at the Under-19 level, were unaffected by relative age. Discussion. The findings of this study highlight the influence of relative age effects for both male and female junior cricket players. Interestingly, there may be an advantage to being lefthanded that is more prevalent at the older (male Under-19; female Under-18) age levels. 
1 Moderating Factors Influence the Relative Age Effect in Australian Cricket

2 Jonathan D Connor ${ }^{1,2}$, Ian Renshaw ${ }^{3}$, Kenji Doma ${ }^{1}$

$3{ }^{1}$ College of Healthcare Sciences, Sport and Exercise Science, James Cook University, Townsville,

4 Queensland, Australia

5 2Department of Sport Sciences and Sport Medicine, National Cricket Centre, Brisbane,

6 Queensland, Australia

$7{ }^{3}$ School of Exercise and Nutrition Sciences, Queensland University of Technology, Brisbane,

8 QLD, Australia

9

10 Corresponding author:

11 Jonathan D Connor ${ }^{1}$

12

13 1 James Cook Dr, Douglas, QLD 4811, Australia

14 Email address: jonathan.connor@jcu.edu.au

15 


\section{Abstract}

17 Background. The relative age effect is a commonly occurring phenomenon whereby there is a tendency for relatively older players to be over represented during high level competitions. This

19 effect is often seen to diminish as player's age, however, there has been far less investigation on other potential moderating factors.

Method. This study investigated the impact of the relative age effect, and potential moderating factors, within the talent selection process of Australian cricket. Relative age distribution of 2415 male and female junior and senior state level cricket players, who played in the Junior National Championships or State competition (senior level) between 2011 and 2015, were analysed.

Results. Players born in the first quartile of the cricket season were significantly over represented in both male Under-15, Under-17, Under-19 and female Under-15 and Under-18 levels. However, there was no significant difference at the senior state level for either male or female cricketers. Further investigation of the relative age effect in the junior talent pathway revealed that male allrounders, batters and pace bowlers, and female all-rounders and batters, born in first quartile were over represented. Right-handed batters and bowlers were also influenced by the relative age effect at all Junior National levels, while left-handed batters and bowlers were only influenced at the Under-15 and Under-17 levels. These results highlight the impact relative age has on junior cricket talent pathways, including sex, age, handedness and primary skills. Only state level, and left-

34 handedness at the Under-19 level, were unaffected by relative age.

Discussion. The findings of this study highlight the influence of relative age effects for both male and female junior cricket players. Interestingly, there may be an advantage to being left-handed that is more prevalent at the older (male Under-19; female Under-18) age levels. 


\section{Introduction}

Analysing junior representative level competitions that are responsible for the selection and development of young talented athletes, have been ideal settings to examine relative age effects (RAE). Sports such as soccer (Gil et al, 2014; van der Honert, 2012; Helsen, Van Winckel, \& Williams, 2005), tennis (Ulbricht et al, 2015), Australian Football (Cripps et al, 2015), athletics (Brazo-Sayavera et al., 2016) and rugby league (Till et al., 2010) have all reported instances of the RAE influencing selection at a representative level. Over representation of relatively older players has been attributed to the likelihood of these players having attained a greater degree of physical maturation compared to their younger counter-parts (maturation-selection hypothesis; BrazoSayavera et al., 2016). However, these advantages are temporary, as both the prevalence of the RAE, and the disparity in physical maturity between players, decreases as players age (Musch \& Grondin, 2001). For example, Woods, Robertson, and Gastin (2015) reported that an Under-18 years AFL academy squad did not in fact over-select relatively older players, nor did players born early in the sporting year possess superior anthropometric or physical abilities. It has been argued that relative age may influence sports selection when physical maturity provides a significant advantage to a performer (Romann \& Fuchslocher, 2014).

Alongside age level, sex and handedness have been identified as potential moderating factors of relative age (Baker, Schorer, \& Cobley, 2009). While these factors have been scarcely explored, preliminary evidence suggests that RAE may be present only in certain sports and dependent on sex. For example, Nakata and Sakamoto (2012) compared multiple sports at a representative level between sex, highlighting an over representation of relatively older male players in baseball, soccer, and track and field, while females exhibited the same phenomenon only in volleyball. Brazo-Sayavera and colleagues (2016) reported data from athletics where 
62 females were not affected by RAE, unlike their male counterparts of the same age. Two 63 explanations have been proposed to explain these findings. Musch and Grondin (2001) highlighted

64 that competition amongst selection is a necessary condition for RAE to occur. They argued that if 65 the playing population pool within a particular sport is relatively small, it is unlikely that relative 66 age will impact selection as there are ample opportunities for almost all players to be selected.

67 Rather, the prevalence of RAE is greater in sports with a large playing population and a lower 68 number of selection opportunities (Helsen, Starkes, \& Van Winckel, 1998). A secondary 69 explanation, building upon the maturation hypothesis, is that females generally mature much 70 earlier during their adolescence than males (Tanner \& Whitehouse, 1976) and the physical 71 development and morphological changes associated with puberty would suggestibly influence 72 females at a younger age. Further research examining RAE in female athletes across multiple age 73 groups is required.

While physical maturity is considered a critical factor of RAE (Musch \& Grondin, 2001), sports involving a multitude of skills may exhibit similar phenomena. Cricket is an ideal example of a multi-skilled sport, whereby players are selected based on their dominant skill attributes. This includes batting, all-rounders (skilled at batting and one form of bowling), wicketkeeping, spin bowling or pace bowling. The importance of physical characteristics such as size and strength has yet to be established for cricket batting. In contrast, fast bowling is more reliant on superior anthropometric and physical characteristics in both male (Bartlett, Stockill, Elliott, \& Burnett, 1996) and female (Stuelcken, Pyne, \& Sinclair, 2007) bowlers. Alternatively, skilled performance

82 in spin bowling has been associated with greater coordinative control (e.g. pelvic rotation; Chin et

83 al., 2009) rather than any specific morphologies. Finally, wicketkeeping, which is primarily a 84 catching task, is unlikely to be advantaged by greater physical maturity and may be less likely 
85 influenced by RAE. Collectively, RAE may affect talent selection in cricket not only due to

86 biological maturation, but by whether maturation can affect the overall performance of the skill.

87 Finally, dominant handedness has been described as another potential moderating factor, with left-

88 handedness offering unique advantages during the early stages of talent development (Wattie,

89 Schorer, \& Baker, 2015). For example, left-handed batters in cricket have previously been reported

90 to have a greater scoring average during a national competition than their right-handed

91 counterparts (Brookes, Bussie 're, Jennions, \& Hunt, 2003). Regarding relative age, left-handers in

92 some sports have been shown to be unaffected, unlike their right-handed counter-parts of the same

93 age (Loffing, Schorer, \& Cobley, 2010). While a neurological explanation has been proposed (see

94 Geschwind and Galaburda, 1987), the more prevalent theory is an innate strategic advantage;

95 coined the 'fighting hypothesis' (Raymond, et al., 1996; Wood \& Aggleton, 1989). This theory

96 highlights an inherent advantage possessed by players with unorthodox actions (such as left-

97 handers), due to the lack of exposure players have competing against those types of performers

98 (also see Goulet, Bard, \& Fleury, 1989). It is currently unclear whether dominant handedness

99 weakens the prevalence of RAE during the adolescent years of talent selection.

100 The FTEM (Foundations, Talent, Elite, and Mastery) framework is a useful model in which

101 to examine how RAE may impact players at the Talent level, through to the Elite level (Gulbin,

102 Croser, Morley, \& Weissensteiner, 2013). For example, the early stages of the Talent level centres

103 on demonstrating potential, and verification of that potential. However, this process may be biased

104 towards relatively older players possessing an innate, albeit temporary, physical advantage over 105 their peers.

106 The purpose of this study was to examine common moderating factors of the RAE in

107 Australian cricket, including age, sex, cricket-specific skills and handedness. It is hypothesised 
108 that the RAE will be most prevalent in younger age groups for both males and females, gradually

109 reducing until (adult state level). That is, relatively older males will be over represented at the

110 Under-15 (U15), Under-17 (U17) and Under-19 (U19) representative levels with similar findings

111 observed for older females in their age group competitions at U15 age group. Dominant skills that

112 are most impacted by early physical maturational factors, such as batting, fast bowling and fast

113 bowling all-rounders are hypothesised to be over represented by relatively older players. Finally,

114 left-handers are hypothesised to be less susceptible to the effect of relative age. Additionally, those

115 relatively older players will not be over represented at the highest age group competition for both

116 males (U19) and females (U18) for both batting and bowling.

117

118 Methods

119 Playing data for all male U15, U17 and U19 and female U15 and U18 junior cricketers

120 who competed in the Annual National Junior championships in Australia between 2011 and 2015

121 was obtained from an open source online database (nationalchamps.com.au), while access to non-

122 identifiable data (i.e. birth date, dominant skill and handedness) was provided by the national

123 organisation (Cricket Australia). Taking into consideration the cut-off date in age group

124 competitions in Australian cricket of August 31 $1^{\text {st }}$, player's relative age was determined by coding

125 player birth-dates into quartiles (Q1: September - November; Q2: December -February; Q3:

126 March - May; Q4: June - August). While previous research on relative ages have often compared

127 birth distribution of their group to an 'assumption of equal distribution' (Loffing, Schorer, \&

128 Cobley, 2010), this study compared skilled cricketers birth distribution to the birthdates of all

129 Australian club cricketers who played in 2015/2016 (Table 1). All players were informed of the

130 activities of the program and voluntarily agreed to participate. This research received institutional 
131 approval from James Cook University (H6267) and was conducted in accordance with the National

132 Statement on Ethical Conduct in Human Research (2007).

133

134 Table 1. Birth quartile distribution of Australian junior and senior club cricketers who played in

135 the $2015 / 2016$ season

\section{**INSERT TABLE 1 NEAR HERE**}

\section{Statistical analysis}

All data are presented as descriptive statistics, including the number of cricket players and their relative percentages. Chi-square analyses were utilised to compare the number of cricket players across different birth quartile distributions (Q1, Q2, Q3 and Q4) who played in the Australian National Cricket Championships between the 2012 and 2015 seasons inclusive. Within each player's age group for male (U15, U17, U19 and state level) and female (U15, U18 and state level) cricket players, they were then further separated into their cricket-specific skill (all-rounders, batters, pace bowlers, spin bowlers and wicketkeepers) and subsequent dominant handedness (left or right) within batting or bowling skill. This was compared to the birth statistics $(n=199,183)$ of Australian cricketers who played in the 2014-2015 competition. Statistical analyses were conducted using SPSS version 22.0 software, while the alpha level was set at 0.05 .

\section{Results}

$151\left(X^{2}=26.50, \mathrm{p}<0.05\right)$ and $\mathrm{U} 19\left(X^{2}=20.00, \mathrm{p}<0.05\right)$ male cricketers participating in the Annual

152 National Championships, however, no significant effect was found for state level players $\left(X^{2}=\right.$

$1536.61, \mathrm{p}=0.08)$. There was an over representation of players born in the first quartile of the year 
154 across U15 (36.1\%), U17 (35.5\%) and U19 (34.2\%) age levels, while the third (U15, 20.1\%; U17,

155 19.9\%; U19, 19.7\%) and fourth birth quartile (U15, 15.7\%; U17, 20.3\%; U19, 20.2\%) were

156 consistently lower than the expected value (Table 1). A main effect was also found for U15 $\left(X^{2}=\right.$

157 34.27, $\mathrm{p}<0.05$; Figure 2) and U18 $\left(X^{2}=28.55, \mathrm{p}<0.05\right)$ female cricketers in the National

158 Championships, however, no effect was found for female state level players $\left(X^{2}=1.34, \mathrm{p}=0.72\right)$.

159 Similar to male cricketers, both U15 and U18 female cricketers had an over represented percentage

160 of players born in the first quartile (37.7\% and $37.0 \%)$, while the fourth quartile (16.0\% and $18.7 \%)$

161 were the lowest represented.

162

**INSERT FIGURE 1 NEAR HERE**

163 Figure 1. Birth quartiles of U15, U17 and U19 junior state level male cricketers. *Statistically 164 significant finding $(\mathrm{p}<0.05)$.

\section{**INSERT FIGURE 2 NEAR HERE**}

166

167 Figure 2. Birth quartiles of U15 and U18 junior state level female cricketers. *Statistically 168 significant finding $(\mathrm{p}<0.05)$.

A main effect was reported for all cricket-specific skills across the male and female player

172 pathway at one or more age levels. However, no effect was reported for any skill at state level for

173 either male or female players. Birth distributions for male all-rounders were significant at the U15

174 and U17 level, however, no difference was found at the U19 or State level. The percentage of

175 players born in the first quartile was the highest among birth distributions for all age levels, while

176 the third and fourth quartile were all lower than the expected value (see Tables $1 \& 2$ ). A main 
177 effect was also found for batting in the U15 and U19 age group levels, and all age level groups for

178 bowlers, with the first quartile being over represented and the last quartile under represented. No

179 effects were reported for spin bowlers or wicketkeepers across any age level.

180 A main effect was found for female all-rounders at the U15 and U18 levels, with the first

181 birth quartile over represented across both age levels. No significant difference was found for

182 female pace bowlers at the U15 or U18 age level. Female U15 spin bowlers were over represented 183 in the second quartile however no difference was found at the U18 level. Finally, a main effect 184 was found for female U18 wicketkeepers, however, not at the U15 level.

185

186 Table 2. Positional Breakdown of U15, U17 and U19 junior state level male cricketers and their 187 birth quartile.

188

189

190

**INSERT TABLE 2 NEAR HERE**

191

*Statistically significant finding $(\mathrm{p}<0.05)$.

192 Table 3. Positional breakdown of U15 and U18 junior state level female cricketers and their birth 193 quartile.

*Statistically significant finding $(\mathrm{p}<0.05)$. 
200 Q4: 15.4\%]), left-handed $\left(X^{2}=10.85, \mathrm{p}<0.05\right.$ [Q1: 40.0\%; Q2: 18.8\%; Q3: 23.5\%; Q4: 17.6\%]) 201 and right-handed $\left(X^{2}=9.80, \mathrm{p}<0.05\right.$ [Q1: 32.8\%; Q2: 27.3\%; Q3: 18.2\%; Q4: 21.7\%]) U17 202 batters, and right-handed $\left(X^{2}=10.84, \mathrm{p}<0.05\right.$ [Q1: 32.0\%; Q2: 28.4\%; Q3: 17.3\%; Q4: 22.3\%]) 203 U19 batters. No difference was evident for left-handed $\left(X^{2}=6.13, \mathrm{p}=0.06\right.$ [Q1: 35.6\%; Q2: 204 21.8\%; Q3: 26.4\%; Q4: 16.1\%]) U19 level batters, or left ( $X^{2}=0.40, \mathrm{p}=0.94$ [Q1: 30.0\%; Q2: $20520.0 \%$; Q3: 25.0\%; Q4: 25.0\%]) or right-hand $\left(X^{2}=6.13, \mathrm{p}=0.11\right.$ [Q1: 33.9\%; Q2: 22.8\%; Q3: 206 18.9\%; Q4: 24.4\%]) State level batters (see Figure 3).

**INSERT FIGURE 3 NEAR HERE**

210 Figure 3. Comparison of birth quartiles and handedness ( $\mathrm{LH}=$ left-hand; $\mathrm{RH}=$ right-hand) for 211 primary skilled batters, all-rounders and wicketkeepers for junior representative male cricketers. $212 *$ Statistically significant finding $(\mathrm{P}<0.05)$.

213 48.0\%; Q2: 20.0\%; Q3: 28.0\%; Q4: 4.0\%]) and right-handed $\left(X^{2}=25.77, \mathrm{p}<0.05\right.$ [Q1: 38.6\%; Q2: 22.8\%; Q3: 21.1\%; Q4: 17.5\%]) U15 batters, and right-handed $\left(X^{2}=10.85, \mathrm{p}<0.05\right.$ [Q1: 40.9\%; Q2: 21.6\%; Q3: 21.1\%; Q4: 16.4\%]) U18 batters. In all groups, Q1 was the most represented in each group, while Q4 was the least represented. No difference was reported for left219 handed $\left(X^{2}=2.57, \mathrm{p}=0.46\right.$ [Q1: 21.7\%; Q2: 34.8\%; Q3: 30.4\%; Q4: 13.0\%]) U18 level batters or 220 left $\left(X^{2}=1.00, \mathrm{p}=0.80\left[\mathrm{Q} 1: 37.5 \%\right.\right.$; Q2: 25.0\%; Q3: 25.0\%; Q4: 12.5\%]) or right-handed $\left(X^{2}=\right.$ 0.69, $\mathrm{p}=0.88$ [Q1: 26.9\%; Q2: 24.0\%; Q3: 26.9\%; Q4: 22.1\%]) State level (see Figure 4). 
225 Figure 4. Comparison of birth quartiles and handedness for primary skilled batters, all-rounders 226 and wicketkeepers for junior representative female cricketers. *Statistically significant finding (P $227<0.05)$.

228

229 Handedness for Bowlers

230 Analysis of bowler's handedness found significant effects for male left-handed $\left(X^{2}=8.12\right.$, 231 $\mathrm{p}<0.05$ [Q1: 44.7\%; Q2: 18.4\%; Q3: 15.8\%; Q4: 21.1\%]) and right-handed $\left(X^{2}=12.45, \mathrm{p}<0.05\right.$

[Q1: 42.6\%; Q2: 21.3\%; Q3: 19.1\%; Q4: 17.0\%]) and right-handed ( $X^{2}=18.48, \mathrm{p}<0.05$ [Q1:

16.7\%; Q3: 12.5\%; Q4: 37.5\%]) or right-hand $X^{2}=2.64, \mathrm{p}=0.45$ [Q1: 30.4\%; Q2: 26.8\%; Q3:

Figure 5. Comparison of birth quartiles and handedness for primary skilled pace bowlers, spin

244 bowlers and all-rounders for junior representative male cricketers. *Statistically significant finding $245(\mathrm{P}<0.05)$. 
For female bowlers, significant effects were found for left-handed $\left(X^{2}=10.43, \mathrm{p}<0.05\right.$

248

250

251

252

253

254

255

256

257

258

259

260 261 finding $(\mathrm{p}<0.05)$.

262

263

264

265

266

267

268 bowlers (see Figure 6).

\section{Discussion}

[Q1: 52.4\%; Q2: 28.6\%; Q3: 9.50\%; Q4: 9.50\%]) and right-handed ( $X^{2}=30.67, \mathrm{p}<0.05$ [Q1:

37.0\%; Q2: 26.3\%; Q3: 23.7\%; Q4: 13.0\%]) U15 bowlers, and right-handed $\left(X^{2}=19.27, \mathrm{p}<0.05\right.$

[Q1: 36.1\%; Q2: 23.9\%; Q3: 22.7\%; Q4: 17.3\%]) U18 bowlers. Similar to batters, all Q1 was the most represented in each of these groups, while Q4 was the least represented. No difference was reported for left-handed $\left(X^{2}=4.22, \mathrm{p}=0.24\right.$ [Q1: 38.9\%; Q2: 25.0\%; Q3: 16.7\%; Q4: 19.4\%])

U18 level bowlers or left $\left(X^{2}=2.80, \mathrm{p}=0.42\right.$ [Q1: 35.0\%; Q2: 30\%; Q3: 10.0\%; Q4: 25.0\%]) or right-handed $\left(X^{2}=3.92, \mathrm{p}=0.27\right.$ [Q1: 28.8\%; Q2: 30.8\%; Q3: 20.2\%; Q4: 20.2\%]) State level

Figure 6. Comparison of birth quartiles and handedness for primary skilled pace bowlers, spin bowlers and all-rounders for junior representative female cricketers. *Statistically significant

\section{**INSERT FIGURE 6 NEAR HERE**}

The aim of this study was to investigate whether there is a RAE in Australian cricket talent pathways. Secondly, what influences do moderating factors have on relative age on those who are selected? As predicted in the hypothesis, the main findings were 1) that a RAE was present for both male and female junior-state representative levels, across all age level competitions; 2) the RAE was less pronounced at a senior state level for both male and females; 3) for males, the effect 
269 was most prevalent for junior batters and pace bowlers (U15, U19; U15, U17 \& U19 level

270 respectively), and all-rounders (U15 and U17 level); 4) for females, all-rounders (U15 and U18)

271 were most affected across both age groups, while batters (U15), spin bowlers (U15) and

272 wicketkeepers (U18) were only impacted at one stage of the pathway; 5) left-handed batters and

273 bowlers were not affected at the U19 level, unlike their right-handed counter-parts.

$274 \quad$ Age and sex

275 Findings of RAE in male cricketers are consistent with the only other cricket study of this

276 nature, which recognized a RAE in a UK County competition (Edwards, 1994). However, this is

277 the first study to identify the prevalence among all major levels of the junior talent pathway for

278 both male and female cricketers. Those born in the first quarter (Q1) of the playing year were

279 significantly over represented at the male U15 (36.1\%), U17 (35.5\%), and U19 level (34.2\%), and

280 female U15 (37.7\%) and U18 level (36.9\%). No differences were found for male (31.2\%) or female

281 (28.4\%) cricketers playing at the senior state level. Interestingly, the magnitude of RAEs in cricket

282 only gradually decrease as player's reach the senior level. Two explanations are put forward to

283 explain this gradual decline in RAE. Firstly, once players are identified as 'talented' and playing

284 in the National junior competition, it is suggested that coaches are more likely to continue

285 providing resources, access to higher level coaching, and more playing opportunities to these

286 players. This can be further evidenced by a brief analysis of all U17 and U19 male players in this

287 dataset, revealing that $61.6 \%$ played in more than one competition and/or year of the National

288 Championships. Secondly, physical maturation, and the associated morphological and cognitive

289 development, may play a role in technical execution and decision-making that underpin skilful

290 performance (Schorer, Baker, Büsch, Wilhelm, \& Pabst, 2009).

$291 \quad$ Cricket-specific skills 
All-rounders born in the first quartile of the sporting year were over represented in every 293 junior age group for both males (U15, U17 and U19 level) and females (U15 and U18 level).

294 Additionally, male batters (except male U17) and pace bowlers were over represented by relatively 295 older players. It has been proposed that RAE may have a greater impact in sports with specific 296 skills that rely on superior physical attributes (i.e. strength, speed, or power). Interceptive timing 297 tasks, such as batting, would likely benefit from greater strength and power production (Miyaguchi 298 \& Demura, 2012), due to its role in producing faster bat swing velocity (DeRenne \& Szymanski, 299 2009). In cricket, the ability to produce a high peak bat velocity alongside superior bat-ball 300 contacts, are important factors when playing attacking strokes (Connor, Farrow, \& Renshaw, 301 2018). For example, Penn and Spratford (2012) highlighted in their review that state level batsmen 302 exhibit lower peak bat velocity $(15.22+/-2.96 \mathrm{~m} / \mathrm{s}$; Elliott et al., 1993) than international level 303 batsmen $(21.20+/-1.80 \mathrm{~m} / \mathrm{s}$; Stuelcken et al., 2005) when playing an off-drive against bowlers.

304 However, bat swing velocity is not the sole factor in successfully intercepting an object powerfully.

305 It is imperative to note that successfully intercepting a cricket ball also requires superior 306 visuomotor skills (Connor, Farrow, \& Renshaw, 2018). Therefore, the performance benefits 307 associated with early physical maturation are only likely to only be a temporary performance 308 advantage. Further research is required to investigate how much of an impact physical maturity 309 (i.e. anthropometric and morphology) has on junior cricket batting skill.

310 While there is scarce literature on the anthropometric characteristics of male or female 311 junior cricket batters, there has been a greater focus on fast bowling. Specifically, the 312 anthropometric and physical characteristics have been shown to be predictors of fast bowling skill 313 in junior cricketers (Pyne et al., 2006; Loram et al., 2005; Wormgoor, Harden, \& McKinon, 2010).

314 This likely explains the over representation of relatively older pace bowlers being selected across 
315 all levels of the male pathway in the current study. Interestingly, this is in contrast to female pace

316 bowlers who were not significantly over represented in first quartile births (see Table 3).

317 Stuelcken, Pyne, and Sinclair (2007) noted that only male fast bowlers had physical characteristics

318 that were proportionately large relative to their height. It is therefore proposed that female pace

319 bowlers are less affected by the maturation hypothesis, and thus RAE.

320 Finally, female spin bowlers (U15 level; 48.1\%) born in the second quartile of the year and

321 wicketkeepers born in the first quartile of the year (U18 level; 52.4\%) were significantly over

322 represented, although such findings were not reported for male spin bowlers and wicketkeepers.

323 While studies examining the physical development of spin bowlers are limited, it is widely

324 accepted that the ability to impart high revolutions on the ball, along with the angle and stability

325 of the ball at the point of release, is associated with a skilful spin bowler (Spratford et al., 2015).

326 Spratford and colleagues, in their examination of pathway (average age 19.6 \pm 3.6 years) and 'elite'

327 spinners (29.6 \pm 7.8 years), found skill level differences in the ball velocity and angle of release

328 between these two groups. It is currently unclear how influential anthropometric traits are to the

329 development of this niche skill. Much like wicketkeeping, there may be a lack of competition pool

330 to influence RAEs in this area. Within a cricket team, it is standard practice to only select one

331 wicketkeeper and one spin bowler; in contrast to the 5-6 batters and 3-4 pace bowlers. Further

332 research is required to explore the impact of physical maturation on spin bowler's and 333 wicketkeeper's skill development in cricket.

$334 \quad$ Handedness

335 Interestingly, there was no significant RAE for left-handers (batting or bowling) at the

336 highest represented junior level for both male (U19) and females (U18), or at state level. This may

337 suggest an advantage to left-handedness in cricket-specific skills as a player matures. There are 
338 two notable theories to explain the higher-than-expected prevalence of left-handers at high levels

339 of competitions. The innate superiority hypothesis poses a neurophysiological explanation, such

340 as a potentially better developed right hemisphere in left-handers, which might allow for superior

341 performance in certain attentional tasks (Geschwind \& Galaburda, 1987; Hageman, 2009).

342 However, another more commonly attributed explanation is the strategic advantage hypothesis,

343 whereby unfamiliar movement patterns to the opposition (i.e. left-handers) may make it more

344 difficult to perceive cues and anticipate opposition actions (Goulet, Bard, \& Fleury, 1989; Müller,

345 Fadde, \& Harbaugh, 2017). Given the number of left-hand dominant batters and bowlers,

346 opportunities to play against right-handers would be far more regular, while right-handers would

347 have limited playing opportunities against left-handed opponents (Hagemann, 2009). In support

348 of this argument was the findings from the 2003 Cricket World Cup, showing that left-handed

349 batters were more successful in scoring runs than their right-handed counterparts (Brookes,

350 Bussie 're, Jennions, \& Hunt, 2003). Interestingly, the most successful teams were also reported to

351 have close to $50 \%$ of the side being left-handed. Given there is a RAE for both left and right-

352 handers during the junior levels of the national competition, the advantages of left-handedness

353 may not be pronounced until players reach senior levels of competition. More research is warranted

354 to examine the performances of different handedness in cricket competitions across different age

355 levels.

356

357

358

Conclusion

The results of this study suggest that RAE is most prevalent around the 15 year old competition age group, for both male and female cricketers. This effect gradually declines in magnitude as player's age and transition through to the FTEM cricket pathway (Gulbin, Croser, 
361 Morley, \& Weissensteiner, 2013). All-rounders, batters and pace bowlers, who are potentially

362 advantaged by early physical maturity, demonstrated the greatest frequency of RAE across age

363 groups. Given the nature of these cricket specific-skills, it is proposed that the maturation

364 hypothesis explains why these skills (i.e., batting and pace bowling) are significantly impacted,

365 while others less reliant on factors underpinned by physical prowess are not (i.e., spin bowling,

366 wicketkeeping). Interestingly, once players reached the U19 age level competition, the RAE was

367 not evident for left-handed batters or bowlers. This finding provides further evidence that the

368 'fighting hypothesis' circumvents the RAE bias in talent selection. It is also therefore critical that

369 administrators, coaches and talent selectors are aware of the impact that RAE has on both male

370 and female players as they traverse the talent pathway. Indeed, Mann and van Ginneken (2017)

371 demonstrated that talent selectors could successfully overcome RAE bias for athlete selection by

372 providing junior players with a jersey number that corresponded to their age relative to their

373 teammates. For example, in a group of 18 , the oldest player would wear a jersey numbered 1 , while

374 the youngest players would wear a jersey numbered 8 . This approach was effective in reducing the

375 prevalence of RAE in talent selection by overtly emphasising relative age and providing additional

376 context (i.e. individual age in relation to the selection cohort) to players performing skilfully. This

377 highlights the need for coaches to be overtly aware of the relative age of players when conducting

378 talent selection practices. It is also recommended that administrators take proactive steps to

379 limiting the prevalence of RAE. For example, given the recent addition of an underage team into

380 certain levels of the National championships competition (e.g. U16 National team competing in

381 the U17 State Nationals competition), talent selectors should evaluate whether this has increased

382 the selection of relatively younger players into State teams; based on the assumption that relatively

383 older players are being selected into the National underage team. 


\section{References}

386 Bartlett, R. M., Stockill, N. P., Elliott, B. C., \& Burnett, A. F. (1996). The biomechanics of fast

387 bowling in men's cricket: a review. Journal of sports sciences, 14(5), 403-424.

388 Brazo-Sayavera, J., Martínez-Valencia, M. A., Müller, L., Andronikos, G., \& Martindale, R. J.

389 (2016). Identifying talented track and field athletes: The impact of relative age effect on

390 selection to the Spanish National Athletics Federation training camps. Journal of sports

391 sciences, 1-7.

392 Chin, A., Elliott, B., Alderson, J., Lloyd, D., \& Foster, D. (2009). The off-break and "doosra":

393 Kinematic variations of elite and sub-elite bowlers in creating ball spin in cricket

394 bowling. Sports Biomechanics, 8(3), 187-198.

395 Connor, J. D., Farrow, D., \& Renshaw, I. (2018). Emergence of Skilled Behaviours in Professional,

396 Amateur and Junior Cricket Batsmen during a Representative Training Scenario. Frontiers in 397 psychology, 9, $2012-2016$.

398 Coutts, A. J., Kempton, T., \& Vaeyens, R. (2014). Relative age effects in Australian Football 399 League national draftees. Journal of sports sciences, 32(7), 623-628.

400 Cripps, A., Hopper, L. S., Joyce, C., \& Veale, J. (2015). Pathway efficiency and relative age in the $401 \quad$ Australian football league talent pathway. Talent Development and Excellence, 7(1).

402 DeRenne, C., \& Szymanski, D. J. (2009). Effects of baseball weighted implement training: A brief 403 review. Strength \& Conditioning Journal, 31(2), 30-37.

404 Edwards, S. (1994). Born too late to win? [Letter to the editor], Nature, 370, 186. 
405 Gibbs, B.G., Jarvis, J.A., \& Dufur, M.J. (2011). The rise of the underdog? The relative age effect 406 reversal among Canadian-born NHL hockey players: A reply to Nolan and Howell. 407 International Review for the Sociology of Sport, 47(5), 644-649.

408 Gil, S. M., Badiola, A., Bidaurrazaga-Letona, I., Zabala-Lili, J., Gravina, L., Santos-Concejero, J., 409 \& Granados, C. (2014). Relationship between the relative age effect and anthropometry, 410 maturity and performance in young soccer players. Journal of sports sciences, 32(5), 479-486. 411 Goulet, C., Bard, C., \& Fleury, M. (1989). Expertise differences in preparing to return a tennis 412 serve: A visual information processing approach. Journal of sport and Exercise Psychology, $413 \quad 11(4), 382-398$.

414 Gulbin, J.P., Croser, M.J., Morley, E.J., \& Weissensteiner, J.R. (2013). An integrated framework 415 for the optimisation of sport and athlete development: A practitioner approach. Journal of sports sciences, 31(12), 1319-1331.

417 Hagemann, N. (2009). The advantage of being left-handed in interactive sports. Attention, 418 Perception, \& Psychophysics, 71(7), 1641-1648.

419 Helsen, W. F., Baker, J., Schoerer, J., Steingroever, C., \& Wattie, N. (2014). The relative age effect 420 in youth chess competition. Journal of Exercise, Movement, and Sport, 46(1), 150.

421 Helsen, W. F., Starkes, J. L., \& Van Winckel, J. (1998). The influence of relative age on success 422 and dropout in male soccer players. American Journal of Human Biology: The Official Journal of the Human Biology Association, 10(6), 791-798.

424 Helsen, W. F., Van Winckel, J., \& Williams, A. M. (2005). The relative age effect in youth soccer 425 across Europe. Journal of sports sciences, 23(6), 629-636.

426 Mann, D. L., \& van Ginneken, P. J. (2017). Age-ordered shirt numbering reduces the selection 427 bias associated with the relative age effect. Journal of sports sciences, 35(8), 784-790. 
428 Miyaguchi, K., \& Demura, S. (2012). Relationship between upper-body strength and bat swing 429 speed in high-school baseball players. The Journal of Strength \& Conditioning Research, 26(7), $430 \quad 1786-1791$.

431 Müller, S., Fadde, P. J., \& Harbaugh, A. G. (2017). Adaptability of expert visual anticipation in 432 baseball batting. Journal of sports sciences, 35(17), 1682-1690.

433 Musch, J., \& Grondin, S. (2001). Unequal competition as an impediment to personal development: 434 A review of the relative age effect in sport. Developmental review, 21(2), 147-167.

435 National Statement on Ethical Conduct in Human Research 2007 (Updated May 2015). The 436 National Health and Medical Research Council, the Australian Research Council and the 437 Australian Vice-Chancellors' Committee. Commonwealth of Australia, Canberra. Available from: https://www.nhmrc.gov.au/guidelines-publications/e72

Romann, M., \& Fuchslocher, J. (2014). Survival and success of the relatively oldest in Swiss youth skiing competition. International Journal of Sports Science and Coaching, 9(1) 347-356.

441 Raymond, M., Pontier, D., Dufour, A. B., \& Moller, A. P (1996) Frequency-depended maintenance 442 of left handedness in humans. Proceedings of the Royal Society of London B, 263, 1627-1633

443 Till, K., Cobley, S., Wattie, N., O'Hara, J., Cooke, C., \& Chapman, C. (2010). The prevalence, 444 influential factors and mechanisms of relative age effects in UK Rugby League. Scandinavian 445 journal of medicine \& science in sports, 20(2), 320-329.

446 Schorer, J., Cobley, S., Büsch, D., Bräutigam, H., \& Baker, J. (2009). Influences of competition 447 level, gender, player nationality, career stage and playing position on relative age 448 effects. Scandinavian journal of medicine \& science in sports, 19(5), 720-730.

449 Stuelcken, M. C., Portus, M. R., \& Mason, B. R. (2005). Cricket: Off-side front foot drives in 450 men's high performance Cricket. Sports Biomechanics, 4(1), 17-35. 
451 Stuelcken, M.C., Pyne, D., \& Sinclair, P. (2007). Anthropometric characteristics of elite cricket 452 fast bowlers. Journal of sports sciences, 25(14), 1587-1597.

453 Ulbricht, A., Fernandez-Fernandez, J., Mendez-Villanueva, A., \& Ferrauti, A. (2015). The relative 454 age effect and physical fitness characteristics in german male tennis players. Journal of sports 455 science \& medicine, 14(3), 634.

456 Wattie, N., Schorer, J., \& Baker, J. (2015). The relative age effect in sport: A developmental 457 systems model. Sports Medicine, 45(1), 83-94.

458 Woods, C. T., Robertson, S. J., \& Gastin, P. B. (2015). Does relative age distribution influence the 459 physical and anthropometric profiles of drafted under 18 Australian footballers? An investigation 460 between the 2010 and 2013 seasons. Talent Development and Excellence, 7(1), 83-90. 
Figure 1

Birth quartiles of U15, U17 and U19 junior state level male cricketers. *Statistically significant finding $(p<0.05)$.

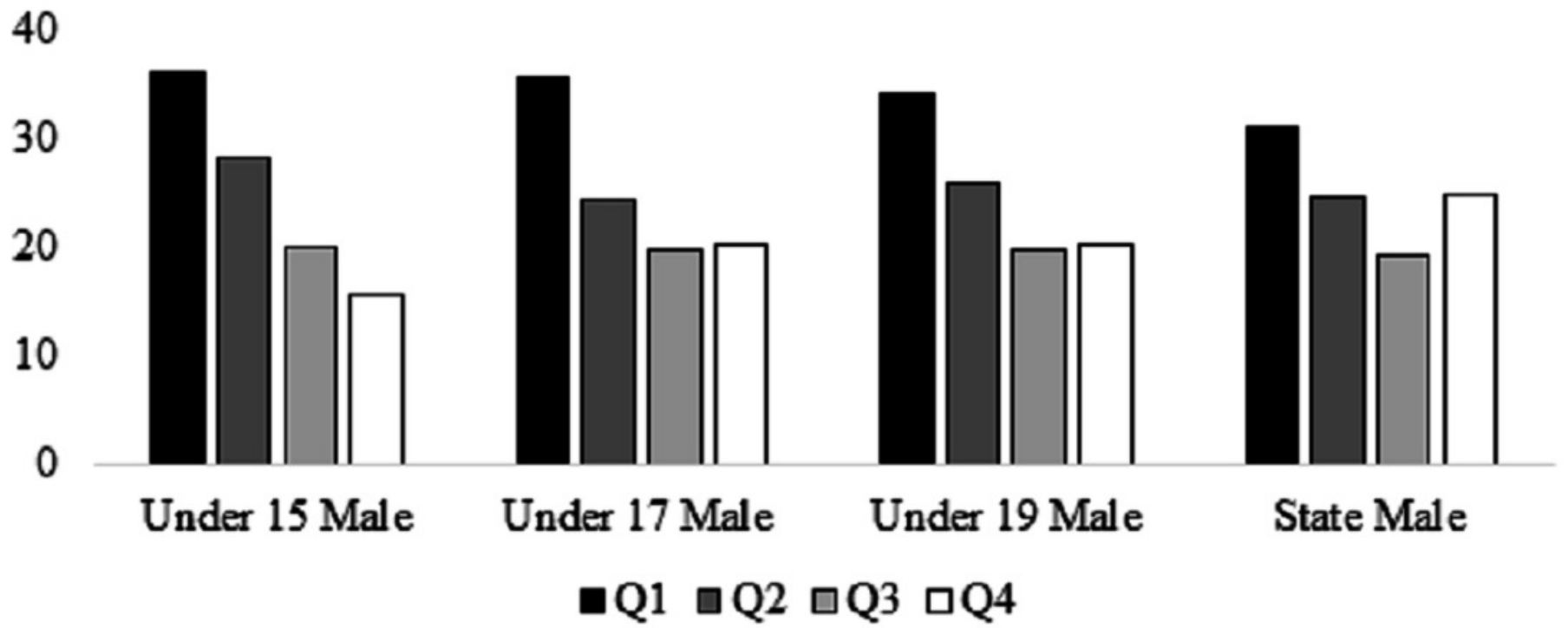


Figure 2

Birth quartiles of U15 and U18 junior state level female cricketers. *Statistically significant finding $(p<0.05)$.

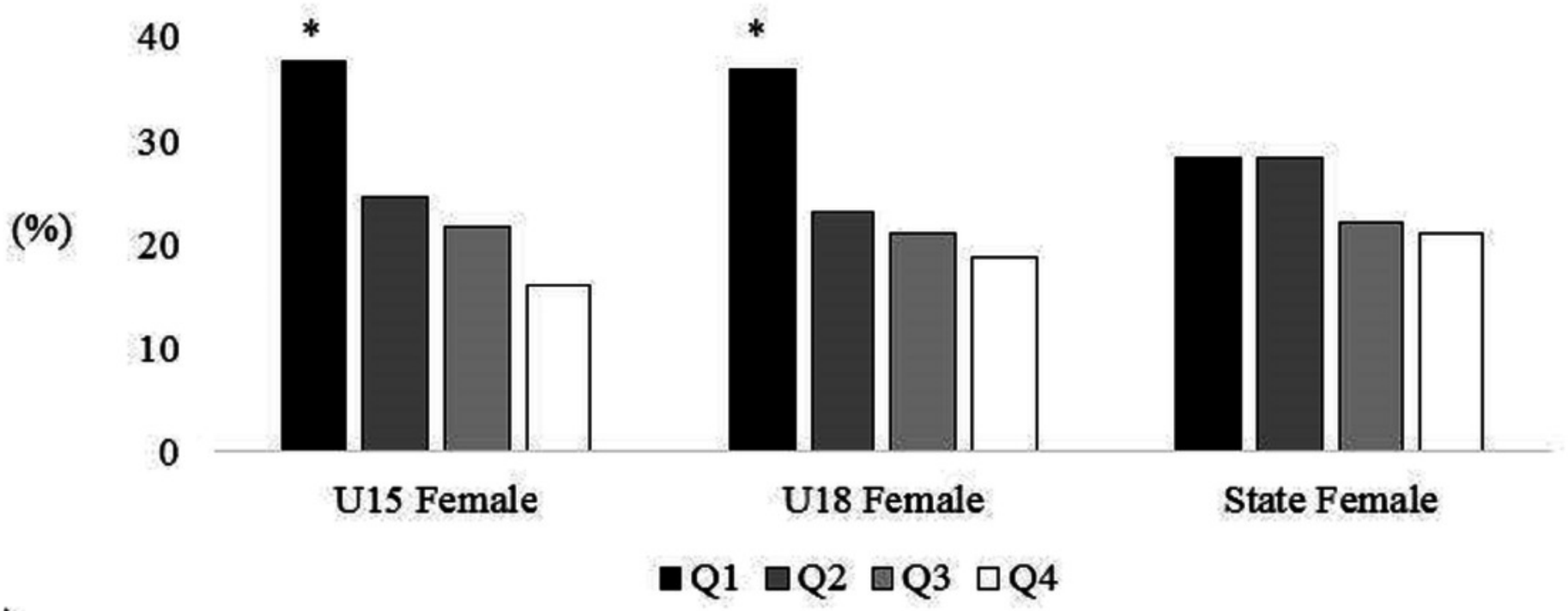




\section{Figure 3}

Comparison of birth quartiles and handedness ( $\mathrm{LH}=$ left hand; $\mathrm{RH}=$ right hand) for primary skilled batters, all-rounders and wicketkeepers for junior representative male cricketers. *Statistically significant finding $(p<0.05)$.

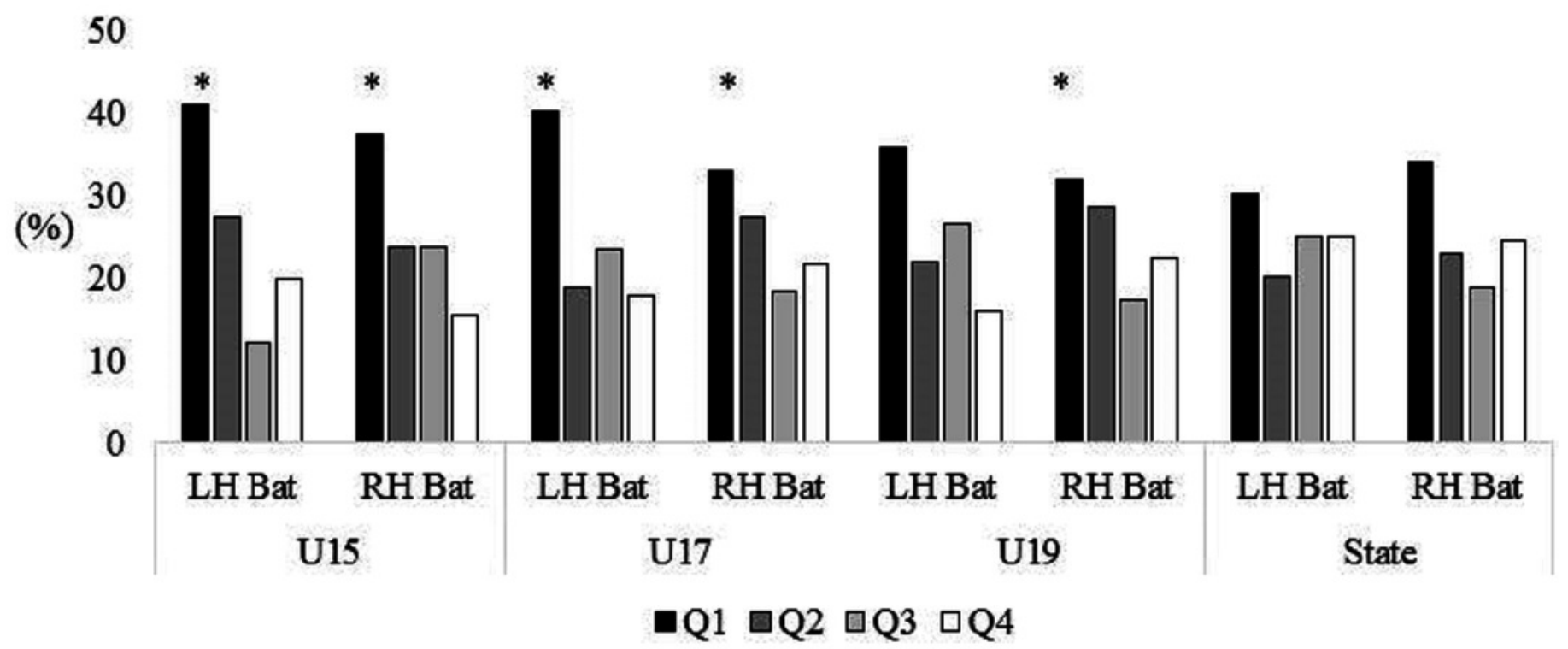




\section{Figure 4}

Comparison of birth quartiles and handedness for primary skilled batters, all-rounders and wicketkeepers for junior representative female cricketers. *Statistically significant finding $(P<0.05)$.

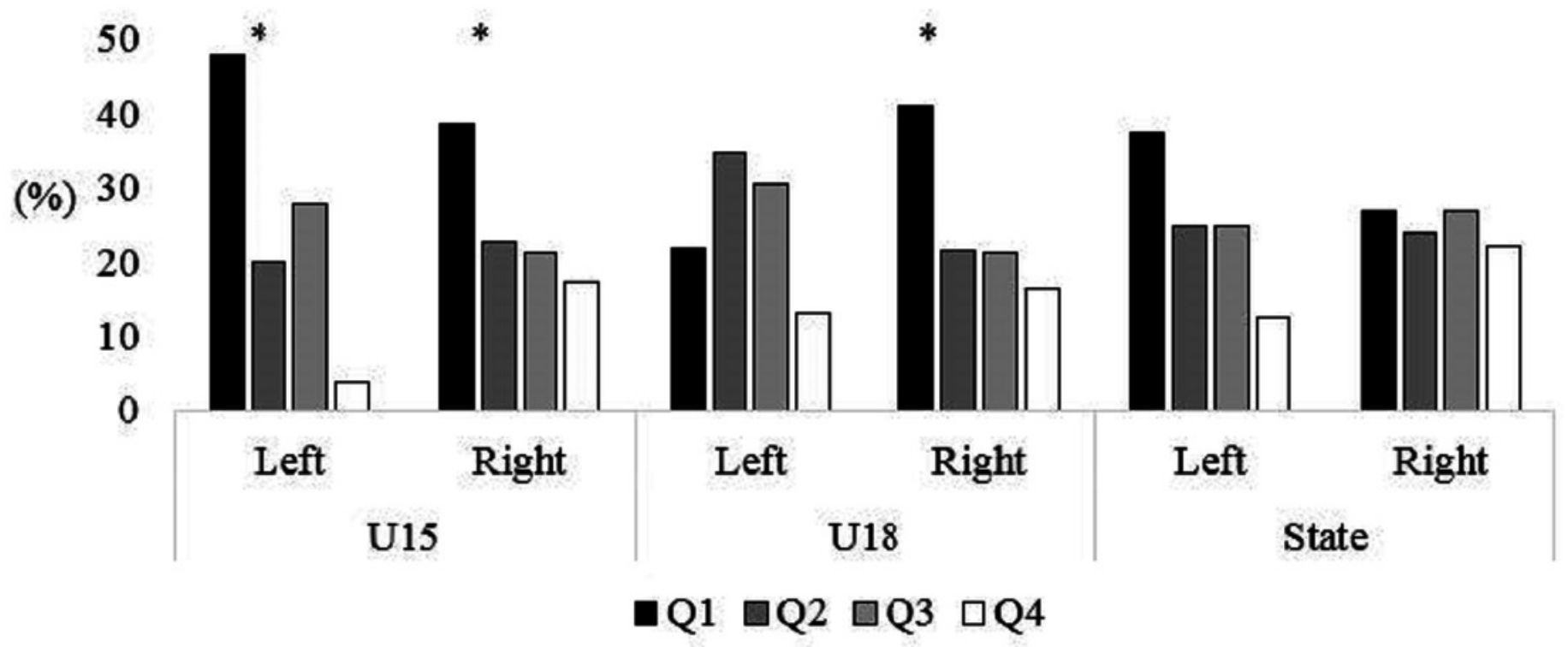


Figure 5

Comparison of birth quartiles and handedness for primary skilled pace bowlers, spin bowlers and all-rounders for junior representative male cricketers. *Statistically significant finding $(p<0.05)$.

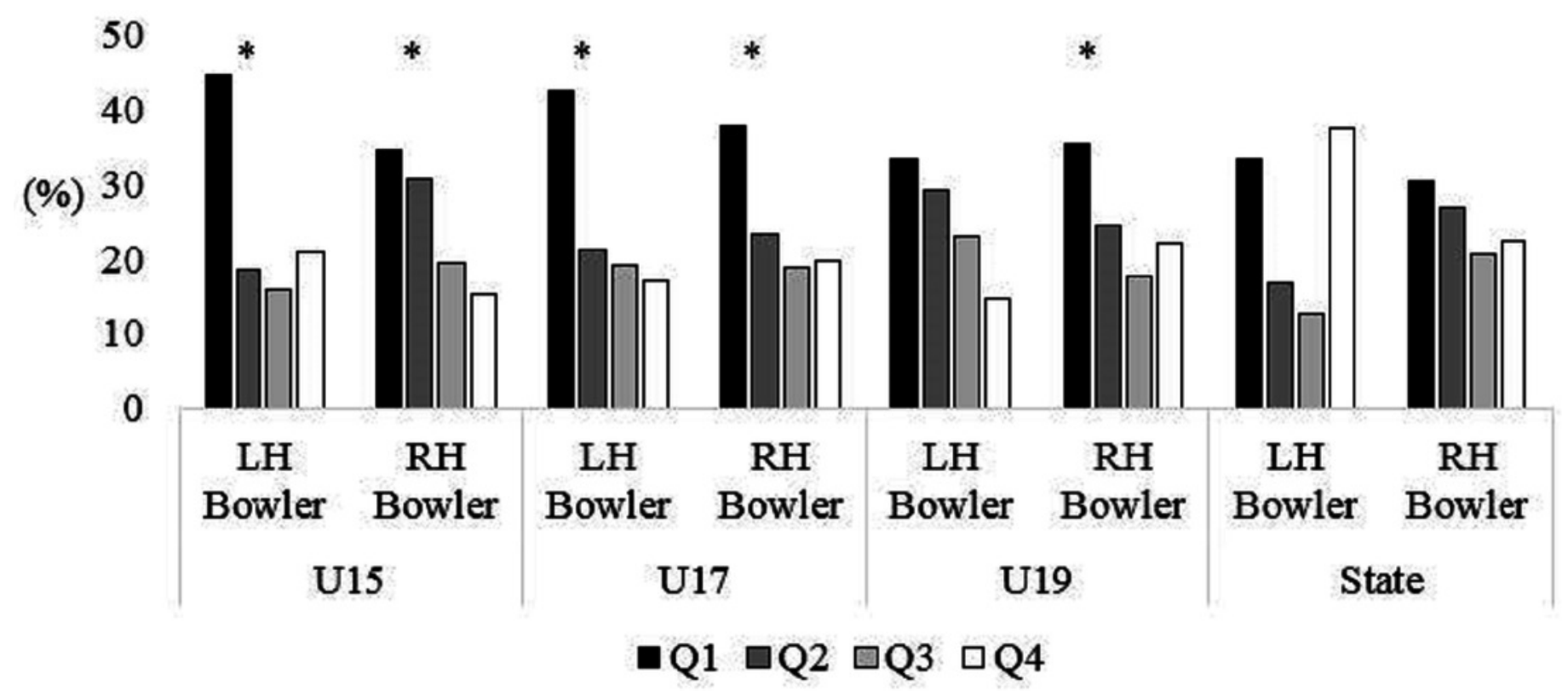


Figure 6

Figure 6. Comparison of birth quartiles and handedness for primary skilled pace bowlers, spin bowlers and all-rounders for junior representative female cricketers. *Statistically significant finding $(p<0.05)$.

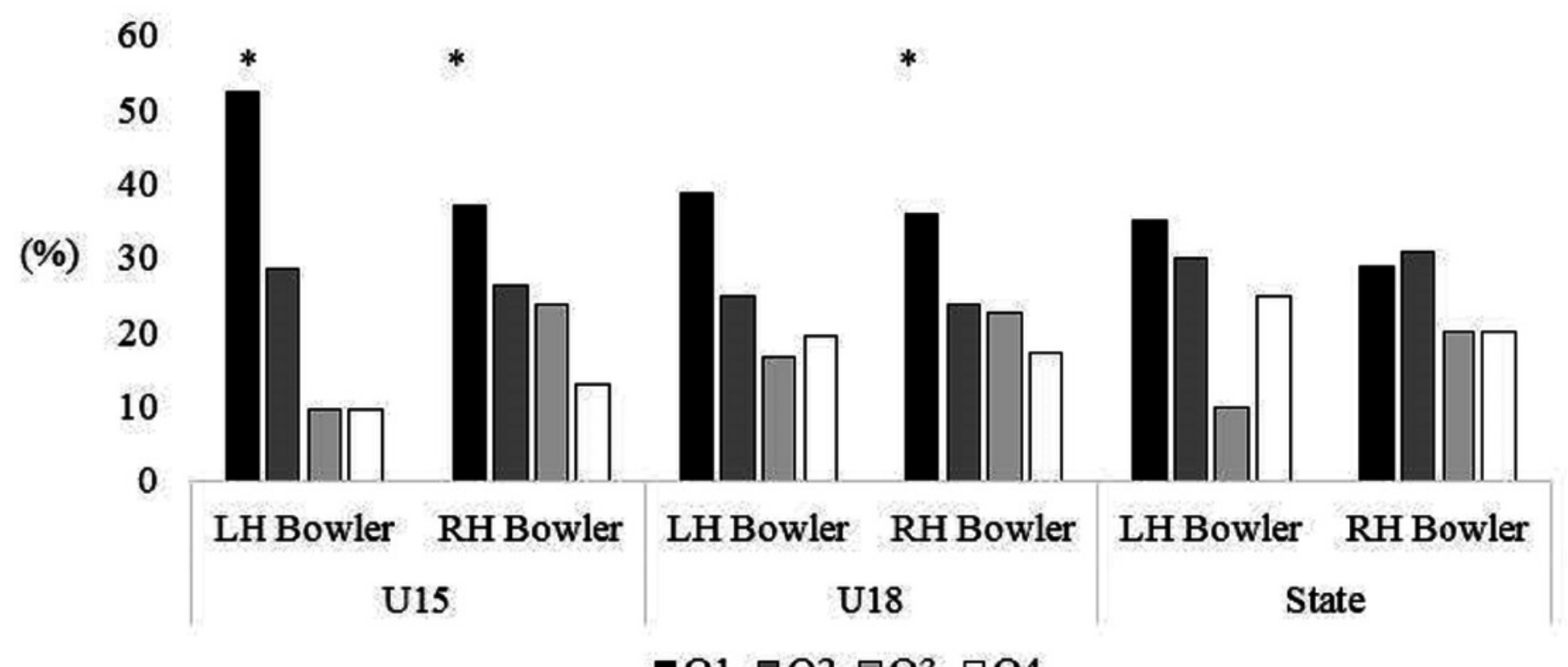

$\square \mathrm{Q} 1 \square \mathrm{Q} 2 \square \mathrm{Q} 3 \square \mathrm{Q} 4$ 


\section{Table $\mathbf{1}$ (on next page)}

Birth quartile distribution of Australian junior and senior club cricketers who played in the $2015 / 2016$ season 
1 Table 1. Birth quartile distribution of Australian junior and senior club cricketers who played in

2 the $2015 / 2016$ season

\begin{tabular}{lcccc}
\hline & Q1 & Q2 & Q3 & Q4 \\
\cline { 2 - 5 } Australian & $50,063(25.13 \%)$ & $55,630(27.93 \%)$ & $46,808(23.50 \%)$ & $46,682(23.44 \%)$ \\
cricketers & & &
\end{tabular}

3 


\section{Table 2 (on next page)}

Positional Breakdown of U15, U17 and U19 junior state level male cricketers and their birth quartile. 
1 Table 2. Positional Breakdown of Under-15, Under-17 and Under-19 junior state level male 2 cricketers over 4 years and their birth quartile.

Birth Quartiles

\begin{tabular}{|c|c|c|c|c|c|c|c|c|c|c|c|}
\hline \multirow{2}{*}{\multicolumn{12}{|c|}{ All-rounder }} \\
\hline & & & & & & & & & & & \\
\hline State Under-15* & 71 & 32 & $(45.1 \%)$ & 16 & $(22.5 \%)$ & 10 & $(14.1 \%)$ & 13 & $(18.3 \%)$ & 16.27 & $<0.05$ \\
\hline State Under-17* & 79 & 34 & $(43.0) \%$ & 18 & $(22.8 \%)$ & 13 & $(16.5 \%)$ & 14 & $(17.7 \%)$ & 14.41 & $<0.05$ \\
\hline State Under-19 & 72 & 24 & $(33.3 \%)$ & 19 & $(26.4 \%)$ & 13 & $(18.1 \%)$ & 16 & $(22.2 \%)$ & 3.66 & 0.30 \\
\hline State Lev & 39 & 15 & $(38.5 \%)$ & 7 & $(18.0 \%)$ & 8 & $(20.5 \%)$ & 9 & $(23.1 \%)$ & 3.97 & 0.26 \\
\hline \multicolumn{12}{|l|}{ Batter } \\
\hline State Under & 132 & 46 & $(34.9 \%)$ & 37 & $(28.0 \%)$ & 27 & $(20.5 \%)$ & 22 & $(16.7 \%)$ & 10.36 & $<0.05$ \\
\hline State Unde & 180 & 60 & $(33.3 \%)$ & 49 & $(27.2 \%)$ & 37 & $(20.6 \%)$ & 34 & $(18.9 \%)$ & 9.47 & 0.07 \\
\hline State U & 182 & 62 & $(34.1 \%)$ & 52 & $(28.6 \%)$ & 39 & $(21.4 \%)$ & 29 & $(15.9 \%)$ & 13.82 & $<0.05$ \\
\hline State Leve & 96 & 29 & $(30.2 \%)$ & 24 & $(25.0 \%)$ & 19 & $(19.8 \%)$ & 24 & $(25.0 \%)$ & 2.08 & 0.56 \\
\hline \multicolumn{12}{|l|}{ Pace Bowler } \\
\hline State U & 74 & 26 & $(35.1 \%)$ & 24 & $(32.4 \%)$ & 17 & $(23.0 \%)$ & 7 & $(9.5 \%)$ & 11.95 & $<0.05$ \\
\hline State Under-17* & 120 & 49 & $(40.8 \%)$ & 28 & $(23.3 \%)$ & 24 & $(20.0 \%)$ & 19 & $(15.8 \%)$ & 17.40 & $<0.05$ \\
\hline State U & 113 & 47 & $(41.6 \%)$ & 26 & $(23.0 \%)$ & 21 & $(18.6 \%)$ & 19 & $(16.8 \%)$ & 17.51 & $<0.05$ \\
\hline State Level & 73 & 19 & $(26.0 \%)$ & 22 & $(30.1 \%)$ & 14 & $(19.2 \%)$ & 18 & $(24.7 \%)$ & 1.80 & 0.62 \\
\hline \multicolumn{12}{|l|}{ Spin Bowler } \\
\hline State Under-15 & 24 & 4 & $(16.7 \%)$ & 8 & $(33.3 \%)$ & 5 & $(20.8 \%)$ & 7 & $(29.2 \%)$ & 1.67 & 0.64 \\
\hline State Under-17 & 49 & 13 & $(26.5 \%)$ & 11 & $(22.5 \%)$ & 10 & $(20.4 \%)$ & 15 & $(30.6 \%)$ & 1.20 & 0.75 \\
\hline State Under-19 & 54 & 13 & $(24.1 \%)$ & 16 & $(29.6 \%)$ & 11 & $(20.4 \%)$ & 14 & $(25.9 \%)$ & 0.96 & 0.81 \\
\hline State Level & 24 & 8 & $(33.3 \%)$ & 5 & $(20.8 \%)$ & 4 & $(16.7 \%)$ & 7 & $(29.2 \%)$ & 1.67 & 0.64 \\
\hline \multicolumn{12}{|l|}{ Wicketkeeper } \\
\hline State Under-15 & 20 & 7 & $(35.0 \%)$ & 3 & $(15.0 \%)$ & 8 & $(40.0 \%)$ & 2 & $(10.0 \%)$ & 5.20 & 0.16 \\
\hline State Under-17 & 24 & 5 & $(20.8 \%)$ & 3 & $(12.5 \%)$ & 6 & $(25.0 \%)$ & 10 & $(41.7 \%)$ & 4.33 & 0.23 \\
\hline State Under-19 & 30 & 8 & $(26.7 \%)$ & 4 & $(13.3 \%)$ & 5 & $(16.7 \%)$ & 13 & $(43.3 \%)$ & 6.53 & 0.09 \\
\hline State Level & 12 & 5 & $(41.7 \%)$ & 2 & $(16.7 \%)$ & 2 & $(16.7 \%)$ & 3 & $(25.0 \%)$ & 2.00 & 0.57 \\
\hline
\end{tabular}

3 *Statistically significant finding $(\mathrm{P}<0.05)$. 


\section{Table 3(on next page)}

Positional breakdown of U15 and U18 junior state level female cricketers and their birth quartile 
1 Table 3. Positional breakdown of Under-15 and Under-18 junior state level female cricketers over

24 years and their birth quartile

Birth Quartiles

\begin{tabular}{|c|c|c|c|c|c|c|c|c|c|c|c|}
\hline \multirow{2}{*}{\multicolumn{12}{|c|}{ All-rounder }} \\
\hline & & & & & & & & & & & \\
\hline State Under-15* & 186 & 77 & $(41.4 \%)$ & 45 & $(24.2 \%)$ & 44 & $(23.7 \%)$ & 20 & $(10.8 \%)$ & 35.29 & $<0.05$ \\
\hline State Under-18* & 169 & 66 & $(39.1 \%)$ & 41 & $(24.3 \%)$ & 41 & $(24.3 \%)$ & 21 & $(12.4 \%)$ & 24.11 & $<0.05$ \\
\hline State Level & 61 & 18 & $(29.5 \%)$ & 16 & $(26.2 \%)$ & 14 & $(23.0 \%)$ & 13 & $(21.3 \%)$ & 0.98 & 0.81 \\
\hline \multicolumn{12}{|l|}{ Batter } \\
\hline State Under-15* & 66 & 27 & $(40.9 \%)$ & 10 & $(15.2 \%)$ & 12 & $(18.2 \%)$ & 17 & $(25.8 \%)$ & 10.49 & $<0.05$ \\
\hline State Under-18 & 67 & 23 & $(34.3 \%)$ & 14 & $(20.9 \%)$ & 11 & $(16.4 \%)$ & 19 & $(28.4 \%)$ & 5.06 & 0.17 \\
\hline State Level & 42 & 10 & $(23.8 \%)$ & 9 & $(21.4 \%)$ & 14 & $(33.3 \%)$ & 9 & $(21.4 \%)$ & 1.62 & 0.66 \\
\hline \multicolumn{12}{|l|}{ Pace Bowler } \\
\hline State Under-15 & 76 & 28 & $(36.8 \%)$ & 18 & $(23.7 \%)$ & 17 & $(22.4 \%)$ & 13 & $(17.1 \%)$ & 6.42 & 0.09 \\
\hline State Under-18 & 102 & 34 & $(33.3 \%)$ & 22 & $(21.6 \%)$ & 18 & $(17.6 \%)$ & 28 & $(27.5 \%)$ & 5.76 & 0.12 \\
\hline State Level & 52 & 16 & $(30.8 \%)$ & 19 & $(36.5 \%)$ & 9 & $(17.3 \%)$ & 8 & $(15.4 \%)$ & 6.62 & 0.09 \\
\hline \multicolumn{12}{|l|}{ Spin Bowler } \\
\hline State Under-15* & 27 & 6 & $(22.2 \%)$ & 13 & $(48.1 \%)$ & 5 & $(18.5 \%)$ & 3 & $(11.1 \%)$ & 8.41 & $<0.05$ \\
\hline State Under-18 & 20 & 6 & $(30.0 \%)$ & 7 & $(35.0 \%)$ & 5 & $(25.0 \%)$ & 2 & $(10.0 \%)$ & 2.80 & 0.42 \\
\hline State Level & 11 & 3 & $(27.3 \%)$ & 3 & $(27.3 \%)$ & 0 & $(0.0 \%)$ & 5 & $(45.4 \%)$ & 4.64 & 0.20 \\
\hline \multicolumn{12}{|l|}{ Wicketkeeper } \\
\hline State Under-15 & 19 & 3 & $(15.8 \%)$ & 6 & $(31.6 \%)$ & 3 & $(15.8 \%)$ & 7 & $(36.8 \%)$ & 2.68 & 0.44 \\
\hline State Under-18* & 21 & 11 & $(52.4 \%)$ & 4 & $(19.0 \%)$ & 5 & $(23.8 \%)$ & 1 & $(4.8 \%)$ & 10.05 & $<0.05$ \\
\hline State Level & 10 & 3 & $(27.3 \%)$ & 3 & $(27.3 \%)$ & 2 & $(0.0 \%)$ & 2 & $(45.5 \%)$ & 0.40 & 0.94 \\
\hline
\end{tabular}

3 *Statistically significant finding $(\mathrm{P}<0.05)$. 